\title{
Protecting Pakistan's health during the global economic crisis
}

\author{
R. Jooma, ${ }^{1,2}$ A. Khan ${ }^{3}$ and A.A. Khan ${ }^{3}$
}

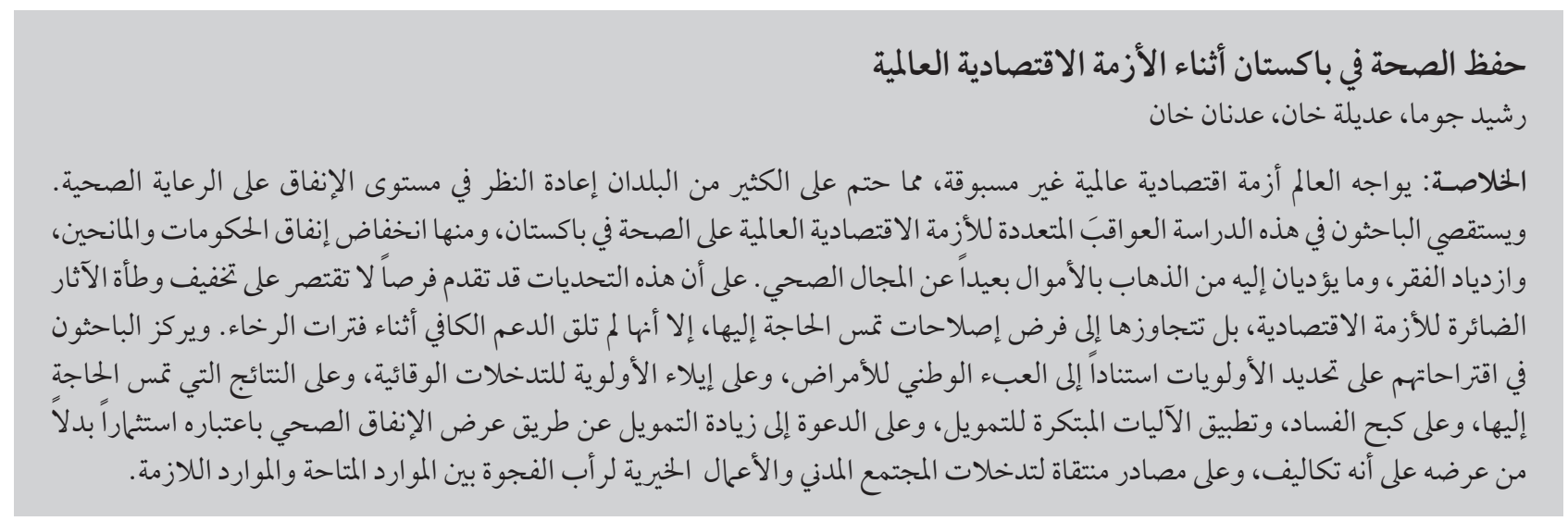

ABSTRACT The world is facing an unprecedented global economic crisis, with many countries needing to reconsider their level of health care spending. This paper explores the many consequences of the global economic turndown on Pakistan's health, including reduced government and donor spending and increased poverty with the consequent diversion of funds away from health. Nevertheless, these challenges may provide opportunities not only to mitigate the adverse effects of the economic crisis but also to institute some muchneeded reforms that may not receive political support during more affluent times. Our suggestions focus on setting priorities based on the national disease burden, prioritizing prevention interventions, demanding results, curbing corruption, experimenting with innovative funding mechanisms, advocating for increased funding by presenting health spending as an investment rather than an expense and by selected recourse to civil society interventions and philanthropy to bridge the gap between available and needed resources.

\section{Protection de la santé au Pakistan pendant la crise économique mondiale}

RÉSUMÉ Le monde fait face à une crise économique sans précédent. En conséquence, de nombreux pays doivent réviser leur niveau de dépenses de santé. Le présent article étudie les nombreux effets de la récession économique mondiale sur la santé au Pakistan, notamment les réductions des dépenses du gouvernement et des bailleurs de fonds et l'augmentation de la pauvreté en raison de l'important détournement des fonds du secteur sanitaire. Toutefois, ces difficultés sont l'occasion non seulement de limiter les dégats de la crise économique, mais aussi d'instaurer des réformes indispensables qui ne recevraient pas d'appui politique lors d'une période prospère. Nos suggestions sont axées sur l'établissement de priorités en fonction de la charge de morbidité nationale ; la sélection des interventions prioritaires ; l'obligation de résultats ; la lutte contre la corruption ; l'expérimentation de mécanismes de financement innovants ; le plaidoyer pour une hausse des fonds en présentant les dépenses de santé comme un investissement plutôt que comme une dépense ; et un recours occasionnel à des interventions de la société civile et à la philanthropie pour combler le fossé entre les besoins et les ressources disponibles. 


\section{Introduction}

The economic crisis that is unfolding globally is at a scale unprecedented since the period before the Second World War. World equity markets lost US\$ 37 trillion in 2008 and rich and poor nations alike face a deep recession. Pakistan is doubly affected since it has not yet recovered from the large increase in oil prices of that year and now has a large fiscal deficit that limits its ability for discretionary spending. Since the government of Pakistan considers much of its health spending as discretionary, allocations for health are likely to decrease.

Economic crises impact health of populations by directly affecting individuals and by reducing governments' health care spending. Individual effects (studied mostly in the developed countries) are manifested in the short term as unemployment leading to restrictions on lifestyle choices. They can even be linked to increased rates of suicide (particularly among the youth) and homicide. Changes in the overall rates of mortality have not been demonstrated, however [1]. These data are from developed countries where health spending has not diminished substantially and where social insurance safety mechanisms provide additional protection. This is not so in developing countries where social protections are weaker and a slowing economy reduces government spending on health and directly affects individuals via unemployment or other forms of diminished income. Evidence shows that economic crises in less affluent countries are accompanied by increased in all-cause mortality, as well as mortality from most of the major specific causes [2].

The Pakistan national health accounts for 2005-06 showed that of the 185 billion Pakistan rupees (PKR) (US\$ 3.08 billion) spent on health in Pakistan, the government contributed PKR 60 billion (32\%) and the private sector, including out-of-pocket payments, contributed around PKR 122 billion (66\%) with donor funds at about PKR 3.6 billion (2\%) [3]. The government's contribution was around $0.7 \%$ of the gross domestic product (GDP). This proportion has remained essentially unchanged for a number of years although the actual amounts have declined when adjusted for inflation. Overall, about US\$19 per capita (government share: US\$ 6) are spent annually on health, compared with the World Health Organization recommended US\$35-50 per capita [4]. However, anomalies exist even within this meagre amount. Within the total, about $80 \%$ is spent on treatment and nearly all spending on prevention comes from government. In this scenario any decrease in the government budget for health will disproportionately curtail prevention programmes. However, in the absence of safety nets, this may largely be eclipsed by lower health spending from individuals as their income diminishes.

This paper explores the reduction in health spending due to the global economic turndown and its impact on the health of Pakistan's population. We also look at how the challenges provide some opportunities to mitigate the adverse effects of the economic crisis, in the form of reforms that have potential longer term benefits for the nation.

\section{Effects of the economic crisis}

\section{Government funding}

Pakistan's GDP is approximately US\$ 163 billion, of which about US\$ 21 billion (about 12\%) are from exports. These revenues are declining due to contracting international markets that limit national earnings, while increasing prices and recent devaluations of the $\mathrm{Pa}$ kistan rupee are making commodities and food more expensive in the international markets. Pakistan saw robust growth during the previous few years; as this growth slows down, revenues for government and hence income for the population will reduce and further constrain the fiscal manoeuvring space available to the government. Finally, government agreements over structural adjustments may further constrain investment in health and development by limiting allocations for personnel, equipment and infrastructure that are crucial for health care provision, controlling preventable diseases and life-saving interventions. Furthermore, as private individuals' ability to pay for health erodes, the public sector may see an increased demand for health care, further constraining the already challenged services. Since facility-based treatments are more visible, the government may shift funding from prevention to treatment or may decrease spending on problems such as environmental pollution and poor sanitation, all of which can have impact on health, as was seen during the last cholera epidemic in Zimbabwe [5].

\section{Decreased individual purchasing power}

Pakistan has scant social security safety nets for its citizens. Most curative health care is paid for by the population directly and the costs often push people into poverty [6]. While trade restrictions insulate many Pakistanis from the economic shockwaves of the international markets, the global turndown has an effect on local markets, which has an impact on local jobs. Around 2\%-3\% Pakistanis work abroad and their remittances are US\$ 7 billion annually, much of which directly supports their families and circulates in the informal economy of Pakistan. Mounting job losses or income reduction for these expatriates and the slowdown in Pakistan's economy has led to real decreases in wages for $45 \%$ of Pakistan's workforce and pushed an additional 6\% Pakistanis into poverty, bringing the total number of people living in poverty to 62 million [7]. 
This unemployment/ underemployment is already decreasing the ability of the public to access health care as seen in the Pakistan economic survey which showed that the proportion of households that could not meet their health care expenses increased from $6 \%$ to $30 \%$ in 2008 [6]. As private health spending is partly discretionary, people may ration their health spending when deciding between food and health. This may already be happening as the poorest households are spending more than $70 \%$ of their income on food or health. They may also prioritize health care within households, further limiting access to care, and the quality of care that is received, by women, children and the poorest [6].

The declining value of the Pakistan rupee against international currencies means that the prices of equipment and medicines may rise [8], compromising people's access to care for chronic diseases that require maintenance treatment, possibly leading to increased morbidity and early mortality. As with other areas, the highest burden of these disparities will be borne by the poorest.

\section{Decreased donor funding}

Donor funding forms 5\% of Pakistan's public sector health expenditure [2], which is low compared to a regional average of about $14 \%$. A decrease in the donor funding is likely as donors' economies shrink, as seen for the Global Fund to Fight AIDS, Tuberculosis and Malaria, which asked the 2008 grantees to scale back their requests for grants. Although small in proportion, donor funds often fill niche roles, such as "jump starting" new initiatives. It is possible that reductions in donor funding may leave gaps in areas such as capacity building, technical assistance etc., which impact on health programmes.

\section{Effect of food crisis}

Along with the economic crisis there is an ongoing global food shortage leading to food price inflation. The food component of the consumer price index in Pakistan increased around $27 \%$ in the period July to April 2008-09 [6], putting $28 \%$ of Pakistanis at risk of severe food insecurity [9]. The food crisis may have serious consequences for health outcomes. People may decide to shift to consumption of unhygienic foods that lead to infections and to cheaper foods of lower nutritional value that compromise their health, eventually placing a greater burden on the health care system. As women and children are seldom the primary bread-winners or primary decision-makers in households [10] they fare worse than men in situations of limited finances. Since they receive a lower priority in allocation of resources they are less able to meet their nutritional requirements [11] and this is reflected by higher mortality among women in the developing world during economic downturns [12].

\section{Possible strategies to protect Pakistan's health}

In most countries there are seldom sufficient funds to meet all the health care needs of the population. These insufficiencies are worse for developing countries, particularly during times of resource constraints. When resources are scarce, it helps to optimize their use with strategies that minimize the harm of decreased funding on health. Funding may be by government, by individuals and by donors.

\section{Response by government}

While increased funding for health is crucial (Pakistan's government spends only US\$ 6 per capita), a case can be made for better use of existing funds. In fact, the fiscal limitations are an opportunity to consider serious reforms that prioritize health problems, increase programmatic and fiscal effectiveness, achieve better results from programmes and prevent diseases, with innovative management and human resource strategies. Political support for these reforms may be more difficult to achieve during more affluent times.

\section{Setting priorities}

Not all diseases are equally important to all nations. Each country must prioritize the diseases that afflict them the most and use knowledge about burden of diseases $(\mathrm{BoD})$ and the impact of health interventions to reduce these burdens. Nearly half the BoD in Pakistan is from diarrhoeal diseases, respiratory disease, hepatitis, tuberculosis, cerebrovascular disease, congenital malformations and injuries [13] (although the data for these BoD are from 1990 [11] and impact assessments of health interventions for these remains unavailable). An updated assessment of the $\mathrm{BoD}$ and the impact of relevant health interventions would help in prioritizing which diseases to fund. However, once such prioritization occurs, the few selected interventions must be adequately funded, rather than spreading the available funds across many interventions. A critical level of investment in an intervention is needed before results are seen and subsequently it may be more cost-effective to build on earlier successes rather than spreading the available resources too thin. Other options may be to consider funding for prevention of chronic diseases as these are seldom covered by private funds, which tend to favour tackling acute ailments.

Interventions work best when they are delivered in a timely way and in the right locations. For example many HIV clinics in Pakistan are severely underutilized as they are situated in cities with few HIV patients live. Similarly, public sexually transmitted infections clinics are generally unjustified in Pakistan since most patients with these infections tend to seek care from the private sector [14]. Antenatal screening of women for HIV has yielded few positive cases at the moment since HIV is uncommon among pregnant women in Pakistan. In contrast, screening for hepatitis B 
may be useful as 1 woman in 40 has this infection and interventions to reduce its transmission from mother to child are available.

\section{Preventive measures}

Curative care is expensive; yet Pakistan spends more than $80 \%$ of its public sector funds on curative care and only about $16 \%$ on prevention [15]. Much of Pakistan's BoD is from preventable conditions, but this continues to mount mainly due to lack of attention to preventive health care strategies. Focusing on disease prevention will likely result in overall cost savings. Smoking and obesity are increasing in Pakistan; the latest figures show that $22 \%$ of urban men and $37 \%$ of urban women are obese [16] and $25 \%$ of men are smokers [17]. Priority prevention efforts may promote lifestyle changes aimed at reducing smoking, obesity or injuries and foster behaviours that reduce or better manage diarrhoeal or respiratory infections. Such measures may include restrictions or bans on smoking and reversing the social stereotypes that glamorize smoking among the youth and favour obesity among the poor.

Diarrhoea causes considerable mortality among infants and morbidity among other age groups. Simple measures such as promoting handwashing can help prevent transmission of diarrhoeal diseases and use of oral rehydration salts in cases of diarrhoea can save lives. Investments in environmental improvements that reduce the contamination of food and water supplies will accentuate these efforts.

\section{Effective utilization of available funds}

Economic crises may represent opportunities to challenge the status quo in health care funding and to usher in reforms that may not be acceptable during more affluent times, as was demonstrated by Thailand after the 1998 economic crisis [18].
Government programmes measure their effectiveness by tracking fund allocations and utilization. Since budgets may be spent without any actual impact in health outcomes, it is essential to measure the outcomes of programmes and to institute measures to identify problems that can jeopardize the results. Governments around the world are increasingly focusing on results by establishing robust measurement mechanisms including surveillance, inproject monitoring and independent evaluations. Data from these sources may be synthesized into information about programme performance. This may be done by specifically developed monitoring and evaluation units within ministries of health that collate the available data about health and its programmes and analyse them to produce evidence-based messages that are directed at particular audiences such as decision-makers, who are also trained in the use of this evidence. An example in the region is the Tehran University Knowledge Translation Centre, which works closely with the Iranian Ministry of Health and is recognized for its excellence in knowledge translation [19].

Using evidence about results and performance to manage programmes will require a major paradigm shift for the government, which will have to reconsider what to do with underperforming programmes or employees and how to reward high achievers, rather than allowing all programmes to proceed unimpeded throughout their tenure. This transition may be difficult, but will ultimately benefit the government by maximizing gains from programmes and directing funding to areas where it is most useful.

One way to assure results is to honour national commitments to achieve of the Millennium Development Goals (MDGs). While many countries appear unlikely to achieve their MDG targets, the initiative has shifted the focus of many governments towards achieving results in key health areas. Pakistan's moderate success in improving maternal health (MDG 5), child health (MDG 4) and tuberculosis/HIV control (MDG 6) should be built on to reduce the overall $\mathrm{BoD}$ and thereby optimize health spending on these areas.

Finally, the problem of corruption is particularly serious in Pakistan [20] and valuable resources are wasted when funds get diverted from their intended purpose. Corruption may be in the form of misappropriation of commodities, equipment or supplies, asking patients for in-kind supplies, tests or informal payments, irregular budget transfers, malprocurement or kickbacks, irregular purchases and petty theft. Control of corruption requires a strong political will with good governance measures, including monitoring results, using electronic systems for inventories and personnel monitoring, online or otherwise transparent bidding for contracts, restricting pharmacies in the public sector to stocking only drugs from the national formulary, developing essential services packages that restrict ad hoc procurements and facilitating cheaper bulk procurements. Other measures such as service structural reforms that place the right personnel in the right jobs and make them more accountable are discussed below.

\section{Optimizing human resources}

Options to help optimize human resources fall into 4 categories: holding employees accountable in their jobs with clearly defined expectations and ongoing evaluations; providing incentives for providers to practise in underserved areas; using non-doctor providers or "physician expanders" to provide basic health needs to those who cannot afford access to physicians; and employing formally trained health managers with an appropriate background in health care.

Rigid management and human resource structures in the Pakistan government make it difficult to dismiss/retire employees or to recruit new ones. Low 
wages and lack of accountability lead sub-optimally paid employees to seek dual employment, obstruct efficient coworkers and even turn to corruption, all of which limit the effectiveness of government programmes. Any substantial reforms must address the issue of accountability for employees, include measures to reward performance and remunerate employees adequately.

Attracting providers to underserved areas of the country has been attempted through a number of approaches. Rationing and quotas of seats in medical colleges for rural residents, with the assumption that they will return to their home towns to practice, has been applied for decades. Yet the strategy seems not to have worked, in part because these doctors were not given sufficient incentives to endure the poor working conditions in rural areas, making their move back to such locations unattractive. In this regard, the experience in $\mathrm{Pa}$ kistan resonates with the unsuccessful efforts by the Australian government to mandate 6 years of rural work for fresh medical graduates [21]. By contrast, the United States successfully attracts doctors and nurses to underserved areas with a combination of loan waivers, higher remuneration and immigration incentives for foreign doctors.

Since physicians are the most expensive health care providers in terms of training and remuneration, it makes sense to shift some of their tasks to other providers. In many countries, basic medical and surgical care is provided by nurses or specifically trained paramedical staff. Global experience suggests that reductions in health care provider costs can be achieved without any reduction in the quality of care that is provided to patients [22,23].

Currently much of the health care management in Pakistan is by doctors who are often not trained as managers. This leads both to inefficient management and suboptimal results, while contributing to a "brain drain" of qualified medical providers out of direct patient care in a country with insufficient numbers of doctors and nurses. Employing non-medically trained health managers may be an option to explore.

\section{Performance-based financing}

The private sector often links the pay of staff to their performance and the concept is being increasingly applied in the public sector. For example, interventions are judged against a predefined set of results and rewards are given for high performance and penalties made for underperformance. Successful examples a found in Mexico, Argentina, Brazil, Afghanistan and Bangladesh, which have increased the rates of usage of primary health care, vaccinations and school attendance for children via these schemes [24]. Often this was achieved at little extra cost, since underpayment to underperforming employees often offset the costs of bonuses. However the success of these schemes depends on the ability to measure results accurately and in real time. Adoption of schemes that measure results has the additional benefit of reducing the opportunities for corruption.

As a corollary of paying providers for performance, provision of incentives to users to take up services has been used very successfully to increase service demand and to provide social support for the poor. For example the Mexican government pays poor families incremental amounts for bringing their children for vaccination and keeping them in school, thus helping to alleviate poverty while at the same time enhancing the uptake of essential preventive health services and education among those who need these the most [25]. These conditional cash transfers could be used for example to increase the uptake of supervised childbirth or vaccinations in Pakistan.

\section{Advocating for increased funding for health}

Currently Pakistan spends about 2\% of its GDP on health, of which $70 \%$ is paid out-of-pocket by the citizens.
Despite the country's GDP increasing from around US\$ 450 per capita in 2002 to around US\$ 850 in 2008, the overall public sector spending on health has remained unchanged at around $0.7 \%$ of GDP, which is a decrease when adjusted for inflation. While the government has periodically aspired to increase its spending on health, until recently it has been constrained by fiscal limitations and its inability to justify the increased investment in health. In part this is because of lack of advocacy for health. The government tends to view funding on health as a drain on funds rather than an investment in the future. This is partly due to the lack of analyses of the long-term costs of ill health and of any cost-effectiveness analysis of interventions that improve population health in Pakistan; these kinds of assessment are routinely done in most developed countries to guide resource allocations. Such analysis would help the Ministry of Health to identify priority interventions and strengthen the case for their funding. Another option would be for the government to define a minimal set of essential health services for the whole population and make a commitment to protect the funding for these services.

\section{Social security nets}

A health care system can be used to provide social security safety nets to the poor. Around $52 \%$ of all catastrophic expenditure in Pakistani households is due to health care [6]. By providing quality inpatient services and medicines in the public sector health facilities, either free of charge or subsidized, the government can reduce the financial burden on the poorest people. However, as was seen in Argentina, as the quality of services improved in the public sector, there was a surge in demand for these facilities that threatened to overwhelm the services [26]. This needs to be anticipated and prepared for. Other options including models of catastrophic health insurance are being piloted in the private sector. The government is considering 
doing this by paying the premiums for the poorest via its extensive Benazir Income Support Scheme which pays cash subsidies for the poor. However, such schemes may be some time away, until the details are worked out, such as how to apply and monitor quality standards in participating facilities, how to determine poverty status and how to deliver payments particularly for afterhours and emergency care.

When used effectively, user fees can reduce the financial burden on government- funded facilities and help improve the quality and the types of services that are provided. In Pakistan most public sector facilities collect only minimal fees from patients (usually < US\$ 0.15). However, the funds thus collected go into a common government Treasury pool and not to the collecting facility itself. Shifting the policy to allow facilities to use funds from user fees for improving their own services would be a positive step.

Mexico, Argentina and Brazil have used conditional cash transfers to alleviate poverty while ensuring health provision. They give financial incentives to families to utilize essential services such as childhood vaccinations and to foster school attendance while providing income support to the poor. Both the services and the payments they receive allow households to shift their available funds to other needs [27].

Nutrition subsidies may protect or even improve the quality and amount of food the very poor eat, as nutrition (both the quality and quantity) tends to suffers first when families have scarce resources for their basic needs [24].

\section{Response by the} private sector

\section{Private sector models}

A number of models have been developed for health care delivery by nongovernmental agencies including the Aga Khan health services, the rural support programmes and the peoples' primary health care initiatives. They have used various styles of management, such as ensuring supplies and personnel and providing subsidies, to improve quality and access to health care for the poor. These lessons must be applied in outsourcing the management of more public health facilities, in order to improve the quality of and access to care and reduce the costs for the neediest in society.

\section{Role of philanthropy}

Pakistan has one of the highest rates of private philanthropy in the world, which supports many important initiatives such as the Shaukat Khanum hospital, the Edhi Foundation, the Aga Khan University, the Sindh Institute of Urology and Transplantation and the Indus hospital. It is possible that the magnitude of the undocumented philanthropy by private individuals/families is underestimated. In 2006, publicly registered companies gave PKR 2.3 billion-equivalent to about half of all donor support — to fund health care in Pakistan. Yet this was less than $1 \%$ of all pre-tax profits of these companies [28]. The magnitude of private philanthropy remains undocumented. If the government can earn the trust of donors to channel these funds more effectively, it may be able to expand access to health care through a larger funding base.

\section{Role of the diaspora}

Nearly 4 million Pakistanis work abroad and remit home US\$ 9 billion annually, according to the most recent estimates of the State Bank of Pakistan. Many of these are highly educated emigrants who have settled in developed countries and give generously to their families. Some of them have initiated and run welfare and other development projects in Pakistan. There is a considerable untapped potential, however, considering that only about $15 \%$ of the US $\$ 1$ billion in donations in cash or kind by expatriate Pakistanis in the United States comes to
Pakistan [29]. However, much of the funding support from the diaspora goes directly to individuals who are identified via family and friends. Few mechanisms exist to transfer funds from private philanthropy into health care. Therefore the potential for transfer of funds and expertise from the Pakistani diaspora to sustainable health projects in Pakistan remain largely untapped.

\section{Response by the donors}

Nearly $5 \%$ of all public sector funding (or about 2\% of all health funding) is supported via direct donor funds [1]. This compares with about $14 \%$ regionally and $21 \%$ for Bangladesh. Much of the donor funding pays for technical assistance and to fund ad hoc projects. In order to optimize the use of funds, it would be helpful if the government can develop priority strategic plans that can guide donor allocations and synergize them with other donors and the government in reaching health outcomes that are of the highest priority in the country and avoid overlap or duplication of programmes. This would encourage transparency and effectiveness, thus easing donor fears about inappropriate use of their funds, and help develop strategies to sustain donor-supported projects after the donors leave. Finally, as a signatory to the International Health Partnership in 2009, the government must agree on a compact with donors to fulfill their obligations including those to the MDGs.

\section{Conclusions}

The global economic crisis will continue to adversely affect health care funding and to jeopardize the health of the population of Pakistan. However, it may represent an opportunity for Pakistan to implement some reforms that may not have been possible without the current pressures to optimize the use of limited 
resources. Beyond the short-term remedies such as protecting payment for an essential set of health services, critical long-term reforms that are long overdue — such as increasing the use of evidence to guide health care policy and programmes, increasing funding for health, prioritizing health funding according to disease burden, focusing on prevention by optimizing the roles of the private sector and donors - may be possible. Thus the global economic crisis represents an opportunity to reform past wrongs and to work towards a better health system in the country.

\section{References}

1. Tapia-Granados J. Increasing mortality during the expansions of the US economy 1990-96. International Journal of Epidemiology, 2005, 34:1194-1202.

2. Falagas ME et al. Economic crises and mortality : a review of the literature. International Journal of Clinical Practice, 2009, 63:1128-1135.

3. National health accounts, Pakistan 2005-06. Federal Bureau of Statistics. 2009. (http://www.who.int/nha/country/pak/ Pakistan_NHA_2005-2006.pdf, accessed 7 February 2012).

4. Spending on health: a global overview. World Health Organization, [online factsheet] (http://www.who.int/mediacentre/ factsheets/fs319/en/index1.html, accessed 7 February 2012).

5. Chambers K. Zimbabwe's battle against cholera. Lancet, 2009, 373:993-994.

6. Pakistan household integrated economic survey. Islamabad, Federal Bureau of Statistics, 2005.

7. Pakistan economic survey 2008-09. Islamabad, Ministry of Finance, 2009.

8. Prices, availability and affordability of medicines in Pakistan. Islamabad, Pakistan, Network for Consumer Protection, 2006.

9. United Nations statement on food security in Pakistan. Islamam bad, United Nations System in Pakistan, 2000 (UN-PAK/ $\mathrm{FAO} / 2000 / 1)$.

10. Jeejebhoy SJ, Sattar ZA. Women's autonomy in India and Pakistan: the influence of religion and region. Population and Development Review, 2001, 27:687-712.

11. Helping women respond to the global food price crisis. Washington DC, International Food Policy Research Institute, 2008 (IFPRI Policy brief No. 007).

12. Baird S, Friedman J, Schady N. Aggregate income shocks and infant mortality in the developing world. Washington DC, World Bank, 2007 (World Bank Policy Research Working Paper No. 4346).

13. Hyder AA, Morrow RH. Applying burden of disease methods in developing countries: a case study from Pakistan. American Journal of Public Health, 2000, 90:1235-1240.

14. Khan AA et al. Care seeking for STI symptoms in Pakistan. The Journal of the Pakistan Medical Association, 2009, 59(9):628-630.

15. Health, Nutrition and Population Unit South Asia Region. Pakistan: towards a health sector strategy. Washington DC, World Bank, 1997 (Report No. 16695-PAK).
16. Nanan DJ. The obesity pandemic-implications for Pakistan. Journal of the Pakistan Medical Association, 2002, 52:342-346.

17. Nasir K and Rehan N. Epidemiology of cigarette smoking in Pakistan. Addiction, 2001, 96(12):1847-1854.

18. Gottret $\mathrm{P}$ et al. Protecting pro-poor health services during financial crises: lessons from experience. Washington DC, World Bank, 2009.

19. Nedjat $\mathrm{S}$ et al. Knowledge transfer in Tehran University of Medical Sciences: an academic example of a developing country. Implementation Science, 2008, 3:39.

20. Global Corruption Report 2007. Berlin, Transparency International, 2007.

21. Sidney CZ. Australian government's plan to address shortage of doctors is rejected. Student BMJ, 2003, 11:263-306.

22. Record JC et al. New health professions after a decade and a half: delegation, productivity and costs in primary care. Journal of Health Politics, Policy and Law, 1980, 5(3):470-497.

23. Laurant $\mathrm{M}$ et al. Substitution of doctors by nurses in primary care. Cochrane Database of Systematic Reviews, 2005, 18(2):CD001271.

24. Gottret P, Schieber GJ, Waters HR. Good practices in health financing: lessons from reforms in low and middle income countries. Washington DC, World Bank 2008.

25. Frenk J et al. Comprehensive health reform to improve health system performance in Mexico. Lancet, 2006, 368:1524-1534.

26. Martinez S. Impact evaluation of maternal child provincial health investment project in Argentina-Plan Nacer. BNPP PPP Health and Education Synthesis Reports. Washington DC, World Bank Netherlands Partnership Program, 2001.

27. Bijlmakers L, Dusseljee J, Jurgens E. The role of user fees and health insurance in health care financing. Positon paper, Summary. Leusden, ETC Crystal (for the Ministry of Foreign Affairs of the Netherlands), 2006.

28. Corporate philanthropy in Pakistan: survey of public listed companies. An Exploratory Survey on the Nature and Dimensions of Corporate Giving in Pakistan. Islamabad, Pakistan Center for Philanthropy, 2006.

29. Philanthropy by Pakistani diaspora in the USA. Islamabad, Pakistan Center for Philanthropy, 2009. 